\title{
Actinin-4 expression in ovarian cancer: a novel prognostic indicator independent of clinical stage and histological type
}

\author{
Sohei Yamamoto ${ }^{1,2}$, Hitoshi Tsuda ${ }^{1,3}$, Kazufumi Honda ${ }^{4}$, Tsunekazu Kita ${ }^{5}$, Masashi \\ Takano $^{5}$, Seiichi Tamai ${ }^{2}$, Johji Inazawa ${ }^{3,6}$, Tesshi Yamada ${ }^{4}$ and Osamu Matsubara ${ }^{1}$ \\ ${ }^{1}$ Department of Basic Pathology, National Defense Medical College, Tokorozawa, Saitama, Japan; \\ ${ }^{2}$ Department of Laboratory Medicine, National Defense Medical College, Tokorozawa, Saitama, Japan; \\ ${ }^{3}$ Core Research for Evolutional Science and Technology of the Japan Science and Technology Corporation, \\ Kawaguchi, Saitama, Japan; ${ }^{4}$ Chemotherapy Division, National Cancer Center Research Institute, Chuo-ku, \\ Tokyo, Japan; ${ }^{5}$ Department of Obstetrics and Gynecology, National Defense Medical College, Tokorozawa, \\ Saitama, Japan and ${ }^{6}$ Department of Molecular Cytogenetics, Medical Research Institute, Tokyo Medical and \\ Dental University, Bunkyo-ku, Tokyo, Japan
}

\begin{abstract}
Actinin-4 is an isoform of non-muscular $\alpha$-actinin and actin-bundling protein. By enhancing cell motility, actinin4 shows different biological properties from another isoform of non-muscular actinin 'actinin-1' and variable clinicopathological implications of actinin-4 have been demonstrated in some human malignancies such as breast cancers, lung cancers, and colorectal cancers. We herein described the clinicopathological and prognostic significance of actinin-4 expression in ovarian cancers. Actinin-4 expression was analyzed immunohistochemically in 265 primary ovarian carcinomas: 116 serous, 71 clear cell, 43 endometrioid, and 35 mucinous adenocarcinomas. With reference to endothelial immunoreactivity, cytoplasmic expression of actinin-4 was classified as either low (including negative) or high. Then, various parameters such as patients' characteristics, histopathological findings including E-cadherin and $\beta$-catenin immunoreactivity, and clinical outcome, were compared between groups showing differences in the intensity or intracellular distribution of actinin-4 immunoreactivity. High expression of actinin-4 was demonstrated in $137(57 \%)$ cases and was associated with serous histology $(P=0.0075)$, high histological grade $(P<0.0001)$, an advanced disease stage $(P=0.036)$, a high degree of residual disease after initial surgery $(P=0.0047)$, poor patient outcome (5-year survival: $52.4 \%$ in the high-expression group vs $\mathbf{7 1 . 9} \%$ in the low expression group, $P=\mathbf{0 . 0 0 4 3}$ by log-rank test), and also with reduced $E$-cadherin and preserved $\beta$-catenin expressions $(P=0.0097$ and 0.017 , respectively). Nuclear immunoreactivity for actinin-4 was detected in 20 (7.5\%) cases and was associated with low histological grade $(P=0.0079)$ but not with other variables. Multivariate analysis showed that high actinin-4 expression was an independent prognostic factor for overall survival, as well as a high degree of residual disease and clear-cell histology. Accumulation of actinin-4 in the cytoplasm may be related to a higher propensity for tumor invasiveness and metastasis, probably by enhancing cell motility, and could be a novel prognostic indicator for patients with ovarian carcinomas.
\end{abstract}

Modern Pathology (2007) 20, 1278-1285; doi:10.1038/modpathol.3800966; published online 14 September 2007

Keywords: actinin-4; cell adhesion; cell motility; ovarian cancer; prognostic factor

Metastasis is a critical process associated with tumor progression, involving several steps beginning with local invasion, followed by infiltration

Correspondence: Dr H Tsuda, MD, Department of Basic Pathology, National Defense Medical College, 3-2 Namiki, Tokorozawa, Saitama 359-8513, Japan.

E-mail: htsuda@ndmc.ac.jp

Received 18 June 2007; accepted 10 August 2007; published online 14 September 2007 into vessels, survival in the circulation, extravasation, and growth at secondary sites. ${ }^{1-3}$ Better comprehension of these steps provides insight into the mechanism of cancer spread, and thus also offers the possibility of devising more efficient forms of therapy for cancer patients. Although the mechanism of local invasion is still largely unknown, one crucial requirement is acquisition and enhancement of cell motility. ${ }^{4}$ Various molecular components of the cytoskeleton, cell adhesion, and signaling 
systems seem to be involved in the regulation of cell motility. ${ }^{5-8}$

Actinin-1 is an isoform of non-muscular $\alpha$-actinin preferentially localized on the inner surface of cells, being a component of focal adhesion plaques and cell-to-cell adherence junctions. Actinin-4, another isoform of non-muscular $\alpha$-actinin, was recently identified as an actin-bundling protein. ${ }^{9}$ The actinin-4 protein is highly concentrated at the leading edge of the cytoplasm of motile cells or actively moving structures such as cell-surface ruffles. $^{9-12}$

The cytoplasmic expression levels of actinin-4 are significantly increased in cells exhibiting enhanced motility. ${ }^{9,10}$ Increased cytoplasmic expression of actinin-4 is reportedly associated with histologically invasive phenotypes of breast cancer, poor prognosis of breast and non-small cell lung cancers, and lymph node metastasis of colorectal cancer. ${ }^{9,10,13}$

Notably, Honda et $a l^{9}$ have also reported the expression of actinin-4 in the nucleus of several cancer cell lines and some low-infiltrative histological subtypes of breast cancer. This nuclear expression was shown to result from translocation of actinin-4 induced by phosphatidylinositol 3-kinase (PI3-K) inhibitor or by cytochalasin D, which inhibits actin polymerization. ${ }^{9}$ Therefore, it has been suggested that nuclear translocation of actinin-4 is caused by loss of its association with the cytoplasmic actin cytoskeleton.

Epithelial ovarian cancer, accounting for $90 \%$ of all ovarian malignant tumors, is the leading cause of death among female genital malignancies. ${ }^{14}$ Because ovarian cancer is often asymptomatic in its early stages, its poor prognosis is attributable to extensive dissemination and metastasis that is already present at the time of diagnosis. Particular cell-to-cell adhesion molecules, especially E-cadherin and associated catenins, are thought to be involved in progression of ovarian cancer. ${ }^{15-19}$ Indeed, downregulation or abnormal expression of E-cadherincatenin proteins has been reported to be associated with poor histologic differentiation of tumors, increased risk of peritoneal metastasis, and poor patient outcome in ovarian cancer as well as in various solid cancers at other primary sites. ${ }^{19-24}$ Although, for disease progression, ovarian cancer cells should require cell motility besides loss of cellto-cell adhesion, the molecular backgrounds underlying this process is still unclear.

In the present study, we immunohistochemically investigated the state of actinin-4 expression in a large series of ovarian cancers applied to tissue microarrays (TMAs). Then to assess the clinicopathological significance of actinin-4 expression, various parameters such as patients' characteristics, histopathological findings including E-cadherin and $\beta$-catenin immunoreactivity, and clinical outcome were compared between groups showing differences in the intensity or intracellular distribution of actinin-4 immunoreactivity.

\section{Materials and methods}

\section{Patients and Tissue Samples}

This study was performed with the approval of the Internal Review Board on ethical issues. All patients involved in the study gave their informed consent to participate. We reviewed the clinicopathological records of 265 patients who had undergone initial surgery followed by platinum-based chemotherapies for primary ovarian cancer at the Department of Obstetrics and Gynecology (National Defense Medical College Hospital, Tokorozawa, Japan) between 1986 and 2004. None of the patients had undergone neoadjuvant chemotherapy or radiation therapy before surgery.

Formalin-fixed paraffin-embedded tissue samples were obtained at the Department of Laboratory Medicine. All pathology specimens were reviewed in our institution, and the histological types of the tumors were classified according to the WHO criteria. $^{25}$ Histological grading, with reference to the grading system proposed by Shimizu et $a l^{26}$ and Silverberg $^{27}$ (Table 1), was performed by two observers independently, and cases without agreement were discussed until a consensus was acquired. The staging of tumors was assigned according to the International Federation of Gynecology and Obstetrics (FIGO) system. The chemotherapeutic regimens comprised cyclophosphamide, doxorubicin and cisplatin (CAP) for 158 patients, paclitaxel and carboplatin (TJ) for 46, irinotecan and cisplatin (CPT-P) for 27, etoposide and cisplatin (EP) for 14, docetaxel and carboplatin (DJ) for 11, cyclophosphamide and cisplatin (CP) for 6, irinotecan and carboplatin (CPT-J) for 2, and cyclophosphamide and carboplatin (CJ) for one.

Clinical response to chemotherapy was evaluated by ultrasonography or computed tomography and classified into complete response (CR), partial response (PR), stable disease (SD), or progressive disease (PD) according to the new Response Evaluation Criteria for Solid Tumours (RECIST) guide-

Table 1 Scoring system used for grading

A

$$
\begin{aligned}
& \text { Predominant architectural pattern } \\
& \text { Score 1: Tubular and/or cystic } \\
& \text { 2: Papillary } \\
& \text { 3: Solid }
\end{aligned}
$$

B

Cytologic atypia Score 1: Slight 2: Moderate 3: Marked

C

Mitotic figures/10 high-power fields ${ }^{\mathrm{a}}$ Score 1: 0-9

2: $10-24$

$3: \geq 25$

Sum of the scores for A, B, and C: $3-5$ grade $1 ; 6,7$ grade $2 ; 8,9$ grade 3 . ${ }^{\mathrm{a}}$ Counted in the most active region at $\times 10 \times 40$ using an Olympus Optiphot Microscope (field area $0.345 \mathrm{~mm}^{2}$ ). 
lines. ${ }^{28}$ Clinical response was assessed for the 85 patients with residual tumors $\geq 2 \mathrm{~cm}$ in size after initial surgery.

Clinicopathological details such as age, FIGO clinical stage, histological type and grade of the tumor, residual tumor after initial cytoreduction, response to chemotherapy, and overall patient survival were assessed for all patients. Details of lymph node status were obtained for 143 cases. Recurrence was assessed for 107 patients for whom complete cytoreduction (optimally no residual disease) was possible, and death caused by recurrent tumor was counted as a recurrence event.

Follow-up was calculated from the date of initial definitive surgery to the date of either last follow-up or death. The average follow-up period after initial surgery was 51.9 months, ranging between 2 and 227 months. Eighty-five (32.1\%) of 265 patients died because of their tumor burden, and 3 patients died due to other causes.

\section{TMA and Immunohistochemistry (IHC)}

To construct TMA blocks, we selected formalinfixed paraffin-embedded cancer tissue blocks from all cases containing the areas that had been used for histological grading. Two core specimens, $2.0 \mathrm{~mm}$ in diameter, for each case were taken from these blocks and transferred to recipient blocks using a Tissue Microarrayer (Beecher Instrument, Silver Spring, MD, USA). These TMA blocks were then cut into 4- $\mu$ m thick sections and subjected to IHC.

The anti-actinin-4 rabbit polyclonal antibody (Ab-2, diluted 1:500) had been raised against the synthetic peptide NQSYQYGPSSAGNGAGC, a unique $\mathrm{N}$-terminal sequence of actinin-4 as described previously. ${ }^{10,29}$ Other primary antibodies used were anti-E-cadherin (clone NCH-38, 1:100, Dako, Glostrup, Denmark) and anti- $\beta$-catenin (rabbit polyclonal, ready-to-use, Lab Vision).

The TMA sections were deparaffinized, subjected to antigen retrieval by autoclaving in sodium citrate buffer (pH 6.0) for $15 \mathrm{~min}$ at $121^{\circ} \mathrm{C}$ for actinin-4, and by heating in a microwave oven in sodium citrate buffer (pH 6.0) for $20 \mathrm{~min}$ at $97^{\circ} \mathrm{C}$ for E-cadherin and $\beta$-catenin, then allowed to cool at room temperature. Endogenous peroxidase was blocked using 5\% hydrogen peroxide, and non-specific staining was blocked in $2 \%$ normal swine serum. The slides were incubated with primary antibodies at $4^{\circ} \mathrm{C}$ overnight and then reacted with a dextran polymer reagent combined with secondary antibodies and peroxidase (Envision Plus; Dako) for $1 \mathrm{~h}$ at room temperature. Specific antigen-antibody reactions were visualized using $0.2 \%$ diaminobenzidine tetrahydrochloride and hydrogen peroxide. Counterstaining was performed using Mayer's hematoxylin.

In the present study endothelium contained in the TMA cores was used as an internal control for actinin-4 (Figure 1a). Normal skin was used as a

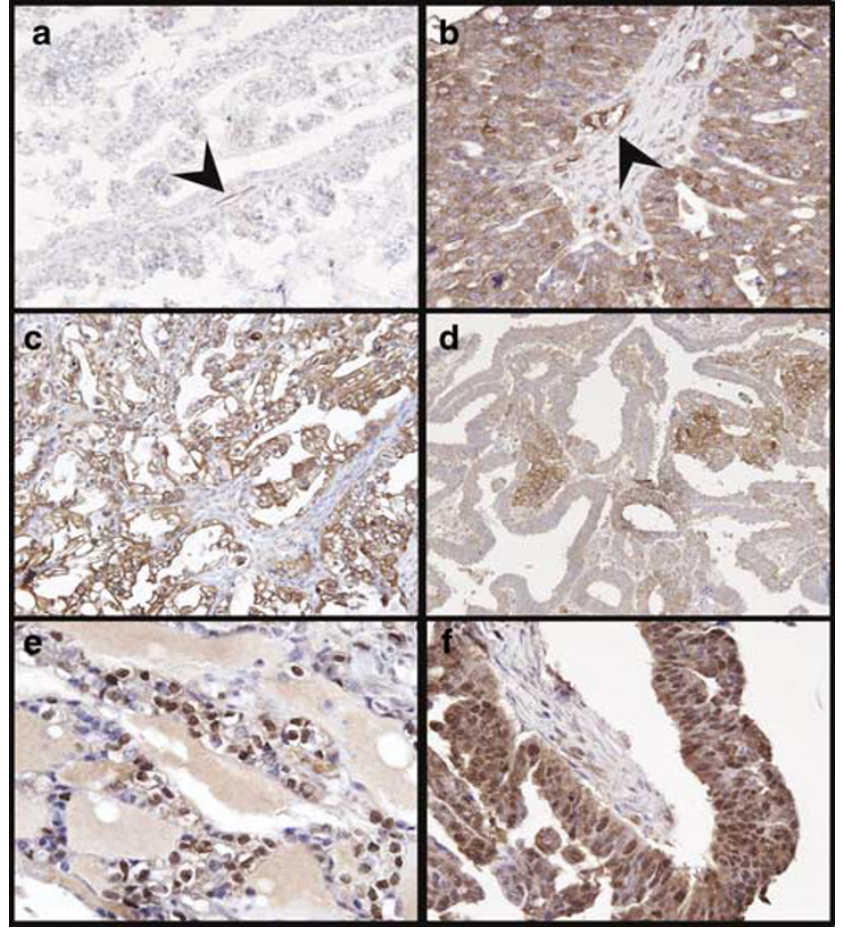

Figure 1 Various immunoreactivities for actinin-4 in ovarian carcinomas. A case of actinin-4-negative clear cell adenocarcinoma $(\mathbf{a}, \times 200)$. Cases with high actinin-4 expression with various subcellular distributions (b-d and f) and cases with nuclear immunoreactivity (e and f). Note the immunoreactivity in capillary endothelial cells (arrowheads in a and b) for comparison with that in tumor cells. A high-grade serous adenocarcinoma showing cytoplasmic immunoreactivity $(b, \times 400)$; a clear cell adenocarcinoma showing predominantly membranous immunoreactivity with various degrees of cytoplasmic immunoreactivity (c, $\times 400)$; a well-differentiated endometrioid adenocarcinoma containing solid components with high actinin-4 expression $(d, \times 100)$; nuclear immunoreactivity in a clear cell adenocarcinoma $(\mathbf{e}, \times 400)$; a case of serous adenocarcinoma showing high actinin-4 expression with nuclear immunoreactivity $(f, \times 400)$ original magnification.

positive control for E-cadherin and $\beta$-catenin. As negative controls, the primary antibodies were omitted from each reaction process, and absence of immunoreactivity was confirmed.

\section{Evaluation of IHC}

To evaluate the results of IHC for actinin-4, the presence and intensity of the immunoreaction, and its intracellular distribution-whether cytoplasmic and/or membranous, nuclear, or a combination of these-were first recorded. An immunoreaction was considered to be present if one or two cores contained some tumor cell nests or at least regional tumor cells showing immunoreactivity for actinin-4 with any intensity or subcellular distribution. By referring to the intensity of endothelial immunoreactivity as a standard, the intensity of cytoplasmic and/or membranous immunoreactivity was divided into one of the two grades: low or high. Actinin-4 
expression was considered to be high if the intensity of the cytoplasmic and/or membranous immunoreactivity was equal to or higher than that in the endothelial cells. Otherwise, actinin-4 expression was defined as low.

We categorized the cytoplasmic and membranous reaction together, because actinin- 4 has been shown to elicit its capacity for enhancing cell motility by bundling the actin-cytoskeleton located at the inner surface of the cytoplasm, where actinin-4 being highly concentrated in membrane ruffles, and also because distinction between cytoplasmic and membranous expression is often difficult in tumor cells with scant cytoplasm..$^{9,10}$

Cell membranous immunoreactivity was used as a reactive parameter for both E-cadherin and $\beta$-catenin, and nuclear immunoreactivity was also assessed for $\beta$-catenin. On the basis of the previous report, membranous immunoreactivity with both anti-E-cadherin and anti- $\beta$-catenin antibodies was scored according to the presence and extent of the immunoreaction, then divided into reduced and preserved groups according to whether immunoreactive tumor cells comprised $<50 \%$ or $\geq 50 \%$ of the total cancer cell population in each core. ${ }^{18}$

Nuclear immunoreactivity for both actinin-4 and $\beta$-catenin was defined as present when one or two cores contained some tumor cell nests or at least regional tumor cells showing immunoreactivity with each antibody.

\section{Statistical Analysis}

Statistical analyses were performed using StatMate III software (ATMS, Tokyo, Japan). Comparisons between parameters were computed by the $\chi^{2}$ test or Student's $t$-test for unpaired data. For survival analysis, Kaplan-Meier curves were drawn and differences between the curves were calculated by the log-rank test. Independent prognostic significance was computed by the Cox proportional hazards general linear model. Differences at $P<0.05$ were considered to be statistically significant.

\section{Results}

\section{Actinin-4-Immunoreaction in Ovarian Carcinomas}

Results of IHC for actinin-4 are summarized in Table 2. Cytoplasmic immunoreactivity was found in 231 $(87.2 \%)$ of the 265 cases: $137(59.3 \%)$ and 128 $(40.7 \%)$ were classified as high expression and low expression, respectively (Figure $1 \mathrm{~b}-\mathrm{d}$ and f). Among the latter, 34 cases with no actinin-4 expression were included.

Nuclear immunoreactivity was identified in 20 $(7.5 \%)$ of the 265 cases: 5 (25\%) cases showed only a nuclear reaction (Figure 1e) and the remaining 15 $(75 \%)$ showed cytoplasmic co-immunoreactivity. Of
Table 2 Actinin-4 immunoreactivity in ovarian carcinomas

\begin{tabular}{lrcr}
\hline Nuclear immunoreactivity & \multicolumn{3}{c}{$\begin{array}{c}\text { Cytoplasmic and/or membranous } \\
\text { immunoreactivity }\end{array}$} \\
\cline { 2 - 4 } & Low & High & Total \\
\hline Absent & 114 & 131 & 245 \\
Present & 14 & 6 & 20 \\
Total & 128 & 137 & 265 \\
\hline
\end{tabular}

the latter 15 cases, 6 (40\%) were considered to have high cytoplasmic expression (Figure 1f).

\section{Correlation between Actinin-4 Expression and Clinicopathological Parameters}

There were no significant differences between the high $(n=137)$ and low $(n=128)$ actinin-4 expression groups with regard to mean patient age, frequency of lymph node metastasis, rate of the chemosensitive tumor and recurrence (Table 3). On the other hand, in comparison with tumors showing low actinin-4 expression, tumors with high actinin-4 expression tended to have an advanced (III/IV) FIGO stage (62\% (85 of 137) vs $49 \%$ (63 of 128), $P=0.036$ ), serous histology (53\% (72 of 137) vs $34 \%$ (44 of 128 , $P=0.0075)$, a high histological grade (grade 3$)(33 \%$ (45 of 137) vs $13 \%$ (16 of 128), $P<0.0001$ ), and a high degree $(\geq 2 \mathrm{~cm}$ ) of residual tumor (41\% (56 of 137) vs $23 \%$ (29 of 128), $P=0.0047$ ) (Table 3 ). Patient survival curves also differed significantly between the two groups $(P=0.0043$, log-rank test; Figure 2). The 5-year survival rates were 52.4 and $71.9 \%$ in the high and low actinin-4 expression groups, respectively.

To assess the clinicopathological significance of actinin-4 nuclear immunoreactivity, the variables used above were compared between cases showing nuclear immunoreactivity (with and without cytoplasmic immunoreactivity) $(n=20)$ and cases showing high actinin-4-expression without nuclear immunoreactivity $(n=131)$ (Table 4). Except for histological grade, no parameters differed significantly between the two groups. Although 45 (34\%) of the 131 tumors showing high actinin-4 expression were histological grade 3 , only $1(5 \%)$ of the 20 tumors showing nuclear immunoreactivity was grade $3(P=0.0079)$.

\section{Correlation between Actinin-4 and E-Cadherin/ $\beta$-Catenin}

Tumors with high actinin-4 expression were more frequently associated with the E-cadherin-reduced phenotype $(P=0.0097)$, and with the $\beta$-cateninpreserved phenotype $(P=0.017)$. Tumors with nuclear actinin-4 immunoreactivity were not associated with the immunoreactive phenotypes of 
Table 3 Correlation of cytoplasmic/membrane actinin-4 expression with clinicopathological parameters in ovarian cancers

\begin{tabular}{|c|c|c|c|c|}
\hline \multirow[t]{2}{*}{ Factor } & \multicolumn{3}{|c|}{$\begin{array}{l}\text { Number of cases (\%) } \\
\text { cytoplasmic/membrane } \\
\text { immunoreactivity }\end{array}$} & \multirow[t]{2}{*}{$\mathrm{P}$-value } \\
\hline & Total & $\begin{array}{c}\text { High } \\
(\mathrm{n}=137)\end{array}$ & $\begin{array}{c}\text { Low } \\
(\mathrm{n}=128)\end{array}$ & \\
\hline Age (years) (median \pm SD) & & $\begin{array}{c}54.6 \\
( \pm 11.1)\end{array}$ & $\begin{array}{c}53.1 \\
( \pm 10.4)\end{array}$ & 0.202 \\
\hline $\begin{array}{l}\text { FIGO stage } \\
\text { I } \\
\text { II } \\
\text { III } \\
\text { IV }\end{array}$ & $\begin{array}{r}85 \\
32 \\
111 \\
37\end{array}$ & $\begin{array}{l}37(44) \\
15(47) \\
60(54) \\
25(68)\end{array}$ & $\begin{array}{l}48(56) \\
17(53) \\
51(46) \\
12(32)\end{array}$ & 0.0356 \\
\hline $\begin{array}{l}\text { Histological subtype } \\
\text { Serous } \\
\text { Clear cell } \\
\text { Endometrioid } \\
\text { Mucinous }\end{array}$ & $\begin{array}{r}116 \\
71 \\
43 \\
35\end{array}$ & $\begin{array}{l}72(62) \\
35(49) \\
14(33) \\
16(46)\end{array}$ & $\begin{array}{l}44(38) \\
36(51) \\
29(67) \\
19(54)\end{array}$ & 0.0075 \\
\hline $\begin{array}{l}\text { Histological grade } \\
\quad 1 \text { or } 2 \\
3\end{array}$ & $\begin{array}{r}204 \\
61\end{array}$ & $\begin{array}{l}92(45) \\
45(74)\end{array}$ & $\begin{array}{r}112(55) \\
16(26)\end{array}$ & $<0.0001$ \\
\hline $\begin{array}{l}\text { Residual tumor (cm) } \\
\quad 0 \\
\quad<2 \\
\quad \geqq 2 \\
\quad \text { Unknown }\end{array}$ & $\begin{array}{r}107 \\
67 \\
85 \\
6\end{array}$ & $\begin{array}{r}47(44) \\
30(45) \\
56(66) \\
4(67)\end{array}$ & $\begin{array}{r}60(56) \\
37(55) \\
29(34) \\
2(33)\end{array}$ & 0.0047 \\
\hline $\begin{array}{l}\text { Lymph node metastasis } \\
\text { Present } \\
\text { Absent } \\
\text { ND } / \text { unknown }\end{array}$ & $\begin{array}{r}40 \\
103 \\
122\end{array}$ & $\begin{array}{l}18(45) \\
47(46) \\
72(59)\end{array}$ & $\begin{array}{l}22(55) \\
56(54) \\
50(41)\end{array}$ & 0.946 \\
\hline $\begin{array}{l}\text { Response to chemotherapies } \\
\text { CR/PR } \\
\text { SD/PD } \\
\text { Unknown }\end{array}$ & $\begin{array}{r}42 \\
35 \\
8\end{array}$ & $\begin{array}{r}26(62) \\
24(69) \\
6(75)\end{array}$ & $\begin{array}{r}16(38) \\
11(31) \\
2(25)\end{array}$ & 0.542 \\
\hline $\begin{array}{l}\text { Recurrence } \\
\text { Yes } \\
\text { No }\end{array}$ & $\begin{array}{l}19 \\
88\end{array}$ & $\begin{array}{l}11(58) \\
36(41)\end{array}$ & $\begin{aligned} 8(42) \\
52(59)\end{aligned}$ & 0.176 \\
\hline 5-year survival (\%) & & 52.4 & 71.9 & 0.004 \\
\hline
\end{tabular}

CR, complete response; FIGO, International Federation of Gynecology and Obstetrics; PD, progressive disease; PR, partial response; SD, stable disease.

Bold values indicate statistical significance.

${ }^{\mathrm{a}}$ When compared between FIGO I/II and III/IV.

${ }^{\mathrm{b}}$ Lymph node biopsy not done.

${ }^{\mathrm{c}}$ Calculated by log-rank test.

E-cadherin or $\beta$-catenin, or with nuclear immunoreactivity for $\beta$-catenin (Table 5 ).

\section{Multivariate Analysis}

Cox univariate analysis including 11 parameters showed that advanced FIGO stage $(P=0.0015)$, the presence of residual tumor $\geq 2 \mathrm{~cm}(P<0.0001)$, a histology of clear cell adenocarcinoma $(P=0.0030)$, and high actinin-4 expression $(P=0.0022)$ were

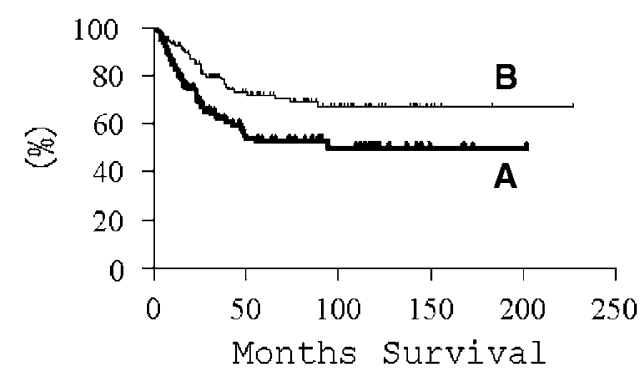

Figure 2 Overall survival curves for 265 patients with ovarian carcinoma, stratified by cytoplasmic actinin-4 immunoreactivity. Curve A for cases with high actinin-4 expression $(n=137)$, and curve B for low actinin-4 expression $(n=128)$.

correlated with worse patient outcome (Table 6a). Additionally, a histology of endometrioid adenocarcinoma was correlated with favorable patient outcome $(P=0.0083)$. Cox multivariate analysis including these five variables identified high actinin-4 expression as an independent prognostic factor for overall survival $(P=0.026)$, as well as the presence of residual tumor $\geq 2 \mathrm{~cm}(P=0.0005)$ and a histology of clear cell adenocarcinoma $(P<0.0001$; Table 6b).

\section{Discussion}

Enhancement of cancer cell motility through remodeling of the actin cytoskeleton plays a crucial role in the process of cancer invasion and metastasis. Bundling of the actin cytoskeleton and its intracellular distribution directly determine cell motility. ${ }^{5}$ $\alpha$-Actinin has been recognized to cross-link actin filaments, and two types of non-muscular $\alpha$-actininactinin-1 and actinin-4-have been identified. ${ }^{30}$ Actinin-1, specifically localized at the ends of actin stress fibers, is thought to be associated with cell adhesion molecules such as integrin- $\beta$ and $\alpha$-catenin, and plays an important role in stabilizing cell adhesion, thus regulating cell shape and cell motility. ${ }^{31,32}$

On the other hand, actinin-4 protein is not localized to focal adhesion plaques or adherens junctions. ${ }^{9}$ Moreover, some cancer cell lines in which actin stress fibers are poorly developed show diffuse dispersal of actinin-4 in the cytoplasm and a high concentration in the cytoplasm in areas where the cell is sharply extended. ${ }^{9}$ The differences in intracellular distribution between these two nonmuscular $\alpha$-actinin isoforms indicate that they have different functions.

In the present study, we compared cytoplasmic actinin-4 expression with its intensity in capillary endothelium, and found that 51.7\% (137 of 265 cases) of ovarian carcinomas showed high expression. High actinin-4 expression in tumors was significantly associated with advanced clinical stage, a serous histology, a high histological grade, a high degree of residual tumor, and a poor patient outcome. 
Table 4 Correlation of nuclear actinin-4 expression with clinicopathological parameters in ovarian cancers

\begin{tabular}{|c|c|c|c|c|}
\hline \multirow[t]{2}{*}{ Factor } & \multirow[t]{2}{*}{ Total } & \multicolumn{2}{|c|}{$\begin{array}{l}\text { Number of cases (\%) } \\
\text { nuclear actinin-4 } \\
\text { expression }\end{array}$} & \multirow[t]{2}{*}{ P-value } \\
\hline & & $\begin{array}{l}\text { Positive } \\
(\mathrm{n}=20)\end{array}$ & $\begin{array}{l}\text { Negative } \\
(\mathrm{n}=131)\end{array}$ & \\
\hline Age (years) (median \pm s.d.) & & $\begin{array}{l}52.9 \\
( \pm 10.3)\end{array}$ & $\begin{array}{l}54.9 \\
( \pm 11.0)\end{array}$ & 0.433 \\
\hline FIGO stage & & & & $0.921^{\mathrm{a}}$ \\
\hline I & 43 & $7(16)$ & $36(84)$ & \\
\hline II & 17 & $2(12)$ & $15(88)$ & \\
\hline III & 65 & $8(12)$ & 57 (88) & \\
\hline IV & 26 & $3(12)$ & $23(88)$ & \\
\hline Histological subtype & & & & 0.663 \\
\hline Serous & 78 & $10(15)$ & $68(85)$ & \\
\hline Clear cell & 39 & $4(10)$ & $35(90)$ & \\
\hline Endometrioid & 16 & $2(13)$ & $14(87)$ & \\
\hline Mucinous & 18 & $4(22)$ & $14(78)$ & \\
\hline Histological grade & & & & $<0.001$ \\
\hline 1 or 2 & 105 & $19(18)$ & $86(82)$ & \\
\hline 3 & 46 & $1(2)$ & $45(98)$ & \\
\hline Residual tumor (cm) & & & & 0.594 \\
\hline 0 & 53 & $9(17)$ & $44(83)$ & \\
\hline$<2$ & 33 & 5 (15) & $28(85)$ & \\
\hline$\geq 2$ & 60 & $6(10)$ & $54(90)$ & \\
\hline Unknown & 4 & $0(0)$ & $4(100)$ & \\
\hline Lymph node metastasis & & & & 0.230 \\
\hline Present & 22 & $5(23)$ & $17(77)$ & \\
\hline Absent & 51 & $6(12)$ & $45(88)$ & \\
\hline $\mathrm{ND}^{\mathrm{b} / \text { unknown }}$ & 78 & $9(12)$ & $69(88)$ & \\
\hline Response to chemotherapies & & & & 0.363 \\
\hline $\mathrm{CR} / \mathrm{PR}$ & 29 & $2(7)$ & $27(93)$ & \\
\hline SD/PD & 28 & $4(14)$ & $24(86)$ & \\
\hline Unknown & 7 & $0(0)$ & $7(100)$ & \\
\hline Recurrence & & & & 0.661 \\
\hline Yes & 12 & $2(17)$ & $10(83)$ & \\
\hline No & 42 & $7(17)$ & $35(83)$ & \\
\hline 5-year survival (\%) & & 50.8 & 54.6 & $0.656^{\mathrm{C}}$ \\
\hline
\end{tabular}

CR, complete response; FIGO, International Federation of Gynecology and Obstetrics; PD, progressive disease; PR, partial response; SD, stable disease.

Bold values indicate statistical significance.

${ }^{\mathrm{a}}$ When compared between FIGO I/II and III/IV.

${ }^{\mathrm{b}}$ Lymph node biopsy not done.

${ }^{\mathrm{C}}$ Calculated by log-rank test.

Multivariate analysis indicated that high actinin-4 expression as well as the extent of residual tumor and the histology of clear cell adenocarcinoma were independent prognostic factors. To our knowledge, this is the first report to describe the state of actinin-4 in ovarian carcinomas and to demonstrate its clinicopathological significance. As well as carcinomas of other organs, such as the breast, colon, and lung, the increased actinin-4 expression in ovarian carcinomas has been suggested to be associated with tumor cell motility, invasiveness, and metastatic potential. The similar clinicopathological impact of actinin-4 expression in carcinomas of different organs suggests that actinin-4 may be universally expressed in various malignant neoplasms and involved in their invasion and metastasis.

In this study, nuclear expression of actinin-4 was recognized in 20 of 265 cases $(7.5 \%)$, and was correlated with low histological tumor grade. Honda et $a l^{9}$ demonstrated that actinin-4 was localized in the nucleus of some solid cancer cell lines and certain populations of breast cancers that showed a low-infiltrative histology. These findings were compatible with the association of nuclear actinin-4 expression with low-grade histology of ovarian cancer in the present study, although the population of cases showing nuclear expression was somewhat small, and there was no relationship between nuclear expression and other clinicopathological variables.

A previous study has demonstrated that nuclear translocation of actinin-4 was introduced by treatment with wortmannin, a PI3-K inhibitor, or with cytochalasin D, an inhibitor of actin polymerization. ${ }^{9} \mathrm{PI} 3-\mathrm{K}$ is thought to be one of the key molecules involved in the signaling pathways of activated receptor tyrosine kinases and in the regulation of cell growth, motility, and morphogenesis. ${ }^{33-35}$

Shayesteh et $a l^{36}$ demonstrated that the copy number of PIK3CA, the gene encoding the P110a catalytic subunit of PI3-K, was increased in approximately $80 \%$ of primary ovarian cancers and several ovarian cancer cell lines. It has also been demonstrated that another PI3-K inhibitor, LY294002, significantly inhibited tumor growth and ascites formation by ovarian carcinoma in vivo and markedly inhibited cancer cell proliferation in vitro, suggesting an important role of PI3-K in the growth of ovarian carcinoma. ${ }^{37}$ Therefore, comprehension of the intracellular dynamics of actinin-4 protein, especially its interaction with PI3-K, may help to reveal possible therapeutic approaches for invasion and metastasis of ovarian cancer.

The inverse relationships between actinin-4/ $\beta$-catenin and E-cadherin immunoreactivity revealed in this study were of considerable interest. Formerly, it had been considered that $\beta$-catenin was a cell adhesion molecule cooperating with the cytoplasmic domain of E-cadherin. In addition, $\beta$-catenin has now been recognized as a multifunctional protein, its functional roles being dependent on the intracellular locations and types of partner proteins with which it forms a complex.

Of these, Hayashida et $a{ }^{38}$ recently demonstrated that, in human colorectal cancer cells, actinin-4 recruits $\beta$-catenin into the actin-rich cytoplasmic portion when E-cadherin expression is decreased. Also, the association of actinin- 4 and $\beta$-catenin was suppressed by transfection with E-cadherin cDNA, but induced by interfering RNA for E-cadherin. ${ }^{38}$ These findings appear compatible with the present 
Table 5 Correlation between actinin-4 and E-cadherin/ $\beta$-catenin

\begin{tabular}{|c|c|c|c|c|c|c|c|}
\hline & \multirow[t]{4}{*}{ Total } & \multicolumn{6}{|c|}{ Number (\%) } \\
\hline & & \multicolumn{2}{|c|}{ E-cadherin } & \multicolumn{4}{|c|}{$\beta$-catenin } \\
\hline & & \multirow[b]{2}{*}{$\begin{array}{c}\text { Preserved } \\
(\mathrm{n}=107)\end{array}$} & \multirow[b]{2}{*}{$\begin{array}{l}\text { Reduced } \\
(\mathrm{n}=158)\end{array}$} & \multirow[b]{2}{*}{$\begin{array}{r}\text { Preserved } \\
(\mathrm{n}=134)\end{array}$} & \multirow[b]{2}{*}{$\begin{array}{l}\text { Reduced } \\
(\mathrm{n}=131)\end{array}$} & \multicolumn{2}{|c|}{ Nuclear immunoreaction } \\
\hline & & & & & & $\begin{array}{l}\text { Present } \\
(\mathrm{n}=17)\end{array}$ & $\begin{array}{c}\text { Absent } \\
(\mathrm{n}=248)\end{array}$ \\
\hline \multirow{2}{*}{\multicolumn{8}{|c|}{$\begin{array}{l}\text { Actinin-4 } \\
\text { Cytoplasmic/ } \\
\text { membrane }\end{array}$}} \\
\hline & & & & & & & \\
\hline High & $137(100)$ & $45(33)$ & $92 *(67)$ & $79^{\dagger}(58)$ & $58(42)$ & $6(4)$ & $131(96)$ \\
\hline Low & $128(100)$ & $62(48)$ & $66(52)$ & $55(43)$ & $73(57)$ & $11(9)$ & $117(91)$ \\
\hline \multicolumn{8}{|l|}{ Actinin-4 } \\
\hline \multicolumn{8}{|l|}{ Nuclear } \\
\hline Present & $20(100)$ & $10(50)$ & $10(50)$ & $11(55)$ & $9(45)$ & $0(0)$ & $20(100)$ \\
\hline Absent & 245 (100) & $97(40)$ & $148(60)$ & $123(50)$ & $122(50)$ & $17(7)$ & $228(93)$ \\
\hline
\end{tabular}

Table 6 Cox model estimates of the significance of prognostic factors

\begin{tabular}{|c|c|c|}
\hline Variables & P-value & $R R(95 \% C I)$ \\
\hline \multicolumn{3}{|l|}{ (a) Univariate Cox regression model } \\
\hline Age $\left(\geq 54^{\mathrm{a}}\right.$ years $v s<54$ years $)$ & 0.341 & $0.81(0.53-1.25)$ \\
\hline FIGO stage (IV/III/II/I) & 0.0015 & $1.36(1.13-1.65)$ \\
\hline Residual tumor $\geq 2 \mathrm{~cm}(v s<2 \mathrm{~cm})$ & $<0.0001$ & $2.62(1.71-4.01)$ \\
\hline Histological grade 3 (vs 2 or 1 ) & 0.520 & $1.17(0.72-1.92)$ \\
\hline \multicolumn{3}{|l|}{ Tumor histology } \\
\hline Serous adenocarcinoma & 0.456 & $1.17(0.77-1.78)$ \\
\hline Clear cell adenocarcinoma & 0.0030 & $1.92(1.25-2.96)$ \\
\hline Endometrioid adenocarcinoma & 0.0083 & $0.35(0.16-0.77)$ \\
\hline Mucinous adenocarcinoma & 0.136 & $0.58(0.28-1.19)$ \\
\hline High actinin-4 expression & 0.0022 & $1.95(1.27-2.98)$ \\
\hline E-cadherin-reduced phenotype & 0.478 & $1.17(0.76-1.78)$ \\
\hline$\beta$-catenin-reduced phenotype & 0.455 & $0.85(0.56-1.29)$ \\
\hline \multicolumn{3}{|l|}{ (b) Multivariate Cox regression model } \\
\hline FIGO stage (IV/III/II/I) & 0.161 & $1.19(0.93-1.51)$ \\
\hline $\begin{array}{l}\text { Residual tumor ( } \geq 2 \mathrm{~cm} \text { vs }<2 \mathrm{~cm} \text { ) } \\
\text { Tumor histology }\end{array}$ & 0.0005 & $2.73(1.55-4.82)$ \\
\hline Clear cell adenocarcinoma & $<0.0001$ & $2.90(1.77-4.76)$ \\
\hline Endometrioid adenocarcinoma & 0.348 & $0.68(0.30-1.52)$ \\
\hline High actinin-4 expression & 0.026 & $1.63(1.06-2.51)$ \\
\hline
\end{tabular}

CI, confidence interval; FIGO, International Federation of Gynecology and Obstetrics; RR, relative risk.

Other abbreviations as in Tables 1 and 2

Bold values indicate statistical significance.

${ }^{\mathrm{a}}$ Mean values.

data, and suggest that molecular and functional association occurs between actinin- 4 and $\beta$-catenin in ovarian carcinomas.

In summary, we have demonstrated that actinin-4, an actin-bundling protein with a capacity for enhancing cell motility, is frequently expressed in ovarian carcinomas. Its highly intense immunoreactivity, probably resulting from cytoplasmic accumulation of actinin- 4 protein, was associated with a histologically high-grade tumor, an advanced clinical stage, a high degree of residual tumor, and a poor patient outcome. IHC for actinin-4 could be a novel prognostic indicator in patients with ovarian carcinoma. Nuclear expression of actinin-4 and its association with the functions of PI3-K would be worth investigating to devise promising therapeutic approaches for actinin-4-positive ovarian carcinomas.

\section{Disclosure/conflict of interest}

This work was supported in part by a grant-in-aid for special research from National Defense Medical College (SY, HT), by a grant-in-aid for 'Program for Promotion of Fundamental Studies in Health Science' conducted by the National Institute of Biomedical Innovation of Japan (TY), and by a grant-in-aid for cancer research from the Ministry of Health, Labor, and Welfare, Japan (HT). The authors state no conflict of interest in this study.

\section{References}

1 Kumar V, Abbas AK, Fausto N (eds). Neoplasia. In: Robbins and Cotran. Pathologic Basis of Disease, 7th edn. Elsevier Saunders: PA, USA, 2004, pp 269-342.

2 Zetter BR. The cellular basis of site-specific tumor metastasis. N Engl J Med 1990;322:605-612.

3 Aznavoorian S, Murphy AN, Stetler-Stevenson WG, et al. Molecular aspects of tumor cell invasion and metastasis. Cancer 1993;71:1368-1383.

4 Partin AW, Schoeniger JS, Mohler JL, et al. Fourier analysis of cell motility: correlation of motility with metastatic potential. Proc Natl Acad Sci USA 1989;86: 1254-1258.

5 Lauffenburger DA, Horwitz AF. Cell migration: a physically integrated molecular process. Cell 1996;84: 359-369. 
6 Wells A. Tumor invasion: role of growth factor-induced cell motility. Adv Cancer Res 2000;78:31-101.

7 Gumbiner BM. Cell adhesion: the molecular basis of tissue architecture and morphogenesis. Cell 1996;84: 345-357.

8 Pantaloni D, Le Clainche C, Carlier MF. Mechanism of actin-based motility. Science 2001;292:1502-1506.

9 Honda K, Yamada T, Endo R, et al. Actinin-4, a novel actin-bundling protein associated with cell motility and cancer invasion. J Cell Biol 1998;23:1383-1393.

10 Honda K, Yamada T, Hayashida Y, et al. Actinin-4 increases cell motility and promotes lymph node metastasis of colorectal cancer. Gastroenterology 2005;128:51-62.

11 Araki N, Hatae T, Yamada $\mathrm{T}$, et al. Actinin-4 is preferentially involved in circular ruffling and macropinocytosis in mouse macrophages: analysis by fluorescence ratio imaging. J Cell Sci 2000;113:3329-3340.

12 Gonzalez AM, Otey C, Edlund M, et al. Interactions of a hemidesmosome component and actinin family members. J Cell Sci 2001;114:4197-4206.

13 Yamagata N, Shyr Y, Yanagisawa K, et al. A trainingtesting approach to the molecular classification of resected non-small cell lung cancer. Clin Cancer Res 2003;9:4695-4704.

14 Seidman JD, Russell P, Kurman RJ. Surface epithelial tumors of the ovary. In: Kurman RJ (eds). Blaustein's Pathology of the Female Genital Tract, 5th edn. Springer-Verlag: New York, 2001, pp 791-904.

15 Risinger JI, Berchuck A, Kohler MF, et al. Mutations of the E-cadherin gene in human gynecologic cancers. Nat Genet 1994;7:98-102.

16 Imai T, Horiuchi A, Shiozawa T, et al. Elevated expression of E-cadherin and alpha-, beta-, gammacatenins in metastatic lesions compared with primary epithelial ovarian carcinomas. Hum Pathol 2004;35: 1469-1476.

17 Voutilainen KA, Anttila MA, Sillanpaa SM, et al. Prognostic significance of E-cadherin-catenin complex in epithelial ovarian cancer. J Clin Pathol 2006;59:460-467.

18 Faleiro-Rodrigues C, Macedo-Pinto I, Pereira D, et al. Association of E-cadherin and beta-catenin immunoexpression with clinicopathologic features in primary ovarian carcinomas. Hum Pathol 2004;35:663-669.

19 Faleiro-Rodrigues C, Macedo-Pinto I, Pereira D, et al. Prognostic value of E-cadherin immunoexpression in patients with primary ovarian carcinomas. Ann Oncol 2004;15:1535-1542.

20 Bankfalvi A, Krassort M, Buchwalow IB, et al. Gains and losses of adhesion molecules (CD44, E-cadherin, and beta-catenin) during oral carcinogenesis and tumour progression. J Pathol 2002;198:343-351.

21 Huiping C, Kristjansdottir S, Jonasson JG, et al. Alterations of E-cadherin and beta-catenin in gastric cancer. BMC Cancer 2001;1:16-25.

22 Krishnadath KK, Tilanus HW, van Blankenstein M, et al. Reduced expression of the cadherin-catenin complex in oesophageal adenocarcinoma correlates with poor prognosis. J Pathol 1997;182:331-338.

23 Kase S, Sugio K, Yamazaki K, et al. Expression of E-cadherin and beta-catenin in human non-small cell lung cancer and the clinical significance. Clin Cancer Res 2000;6:4789-4796.
24 Yoshida R, Kimura N, Harada Y, et al. The loss of E-cadherin, alpha- and beta-catenin expression is associated with metastasis and poor prognosis in invasive breast cancer. Int J Oncol 2001;18:513-520.

25 Tavassoli FA, Devilee P, (eds). World Health Organization classification of tumours. Pathology and Genetics of Tumours of the Breast and Female Genital Organs. IARC Press: Lyon, 2003, pp 218-228.

26 Shimizu Y, Kamoi S, Amada S, et al. Toward the development of a universal grading system for ovarian epithelial carcinoma: testing of a proposed system in a series of 461 patients with uniform treatment and follow-up. Cancer 1998;82:893-901.

27 Silverberg SG. Histopathologic grading of ovarian carcinoma: a review and proposal. Int J Gynecol Pathol 2000;19:7-15.

28 Therasse P, Arbuck SG, Eisenhauer EA, et al. New guidelines to evaluate the response to treatment in solid tumors. European Organization for Research and Treatment of Cancer, National Cancer Institute of the United States, National Cancer Institute of Canada. J Natl Cancer Inst 2000;92:205-216.

29 Kaplan JM, Kim SH, North KN, et al. Mutations in ACTN4, encoding alpha-actinin-4, cause familial focal segmental glomerulosclerosis. Nat Genet 2000;24: 251-256.

30 Youssoufian H, McAfee M, Kwiatkowski DJ. Cloning and chromosomal localization of the human cytoskeletal alpha-actinin gene reveals linkage to the betaspectrin gene. Am J Hum Genet 1990;47:62-72.

31 Otey CA, Vasquez GB, Burridge K, et al. Mapping of the alpha-actinin binding site within the beta 1 integrin cytoplasmic domain. J Biol Chem 1993;268:21193-21197.

32 Knudsen KA, Soler AP, Johnson KR, et al. Interaction of alpha-actinin with the cadherin/catenin cell-cell adhesion complex via alpha-catenin. J Cell Biol 1995;130:67-77.

33 Raffioni S, Bradshaw RA. Activation of phosphatidylinositol 3-kinase by epidermal growth factor, basic fibroblast growth factor, and nerve growth factor in PC12 pheochromocytoma cells. Proc Natl Acad Sci USA 1992;89:9121-9125.

34 Roche S, Downward J, Raynal P, et al. A function for phosphatidylinositol 3-kinase beta (p85alphap110beta) in fibroblasts during mitogenesis: requirement for insulin- and lysophosphatidic acidmediated signal transduction. Mol Cell Biol 1998;18: 7119-7129.

35 Kulik G, Klippel A, Weber MJ. Antiapoptotic signalling by the insulin-like growth factor I receptor, phosphatidylinositol 3-kinase, and Akt. Mol Cell Biol 1997; 17:1595-1606.

36 Shayesteh L, Lu Y, Kuo WL, et al. PIK3CA is implicated as an oncogene in ovarian cancer. Nat Genet 1999;21:99-102.

$37 \mathrm{Hu}$ L, Zaloudek C, Mills GB, et al. In vivo and in vitro ovarian carcinoma growth inhibition by a phosphatidylinositol 3-kinase inhibitor (LY294002). Clin Cancer Res 2000;6:880-886.

38 Hayashida Y, Honda K, Idogawa M, et al. E-cadherin regulates the association between beta-catenin and actinin-4. Cancer Res 2005;65:8836-8845. 